Derecho \& Realidad

Núm. 23 • I semestre de 2014

Facultad de Derecho y Ciencias Sociales, UPTC

ISSN: 1692-3936

\title{
La tortura como crimen de lesa humanidad. Un análisis a la luz de instrumentos internacionales
}

\author{
The torture is a crime against humanity. \\ Analysis from international instruments
}

Edwin Hernando Alonso Niño*

\section{Resumen}

Los llamados "crímenes de lesa humanidad" son tema de actualidad, considerándose un acontecimiento el hecho de instaurar una verdadera cultura de respeto a los derechos humanos; se puede percibir el auge que han tomado y su relevancia en materia de regulación y discusión jurídica.

El presente análisis pretende dar una mirada global a los diversos instrumentos internacionales aplicables al crimen de tortura. En la primera parte de este trabajo se abordará el concepto de "crimen de lesa humanidad", analizando concretamente el tratamiento que se le da al delito de tortura. Tomaremos el desarrollo y el manejo jurídico de un elemento utilizado por los diferentes estamentos internacionales referente a la imprescriptibilidad de los delitos catalogados como de lesa humanidad (Parenti, P. 2007).

\section{Palabras clave}

Tortura, crimen de lesa humanidad, derecho internacional.

\footnotetext{
Abogado Universidad Santo Tomás, investigador auxiliar de la Universidad Santo Tomás, Tunja. Artículo de avance de investigación. Semillero de investigación sobre derecho penal internacional y tortura: Grupo de Investigaciones Socio-Jurídicas. Correo electrónico: alonsinf1@hotmail.com
} 


\section{Abstract}

The so-called "crimes against humanity" are topical, considering an event the fact of establishing a genuine culture of respect for human rights; we can identify the boom that have taken and their relevance in the field of regulation and legal argumentation.

This analysis aims to take a global look at the various international instruments that are applicable to the crime of torture. First, this job implicates the "crimes against humanity" concept, analyzing the specific treatment that is applicable to the crime of torture. We take the development and legal management of an element used by international institutions respect the imprescriptibly of the crimes considerate as crimes against humanity. (Parenti, p. 2007).

\section{Key words}

Torture, crime against humanity, international law. 
"Estos son los hechos; funestos, inmundos y sustancialmente incomprensibles. ¿Por qué, cómo llegaron a producirse? ¿Se repetirán?".

Primo Levi (Vivir para Contar, 2010)

\section{Introducción}

La tortura ha sido considerada como un acto que agravia a la humanidad, en cuanto es uno de los delitos que destruyen lo más preciado de la persona humana $-s u$ integridad humana-, de ahí que en diversas legislaciones internacionales se haya considerado incluso como un crimen de lesa humanidad (Focault, 1995).

Dentro del presente estudio se realizará un análisis global sobre el crimen de la tortura bajo los postulados del derecho internacional, configurándose como necesario describir de manera general la aplicación y el manejo que se ha dado respecto del tema, y de esta manera, vislumbrar la importancia que implica un tema como el presente teniendo como derrotero los derecho humanos, y así mismo la inclusión de crímenes y de daños mentales catalogados como de lesa humanidad.

Es fundamental establecer el impacto que generan este tipo de hechos, sus repercusiones dentro del marco internacional, basándonos en antecedentes jurídicos que permiten dilucidar el tratamiento general frente al delito de tortura, teniendo en cuenta que al ser elevado a la categoría de crimen de lesa humanidad se incorporan al mismo, elementos únicos de transcendental importancia en el momento de su aplicación como puede ser la ofensa que se genera a la humanidad.

Con base en lo anterior, al tener claros estos conceptos, nos enfocaremos en un elemento de especial desarrollo y evolución jurídica que se circunscribe a los llamados "Crímenes de lesa humanidad", como lo es la imprescriptibilidad, y en específico la aplicación de dicho concepto al delito de tortura, estudiando pronunciamientos de instrumentos internacionales que se desarrollarán en el cuerpo del trabajo.

En virtud de lo anterior, se invita al lector a considerar la importancia del tema con base en lo que se expone a continuación, recordando que se establecen herramientas jurídicas que permiten defender la tesis que se planteará y así mismo será factible la interpretación de un crimen como la tortura bajo la óptica de lesivo contra la humanidad generando las correspondientes consecuencias físicas, morales y psicológicas que se derivan de este tipo de conducta. 


\section{Explicación metodológica}

\subsection{Planteamiento del problema}

Por regla general, bajo el Estatuto de Roma de la Corte Penal Internacional de 2002, para considerar el delito de tortura como de lesa humanidad han de concurrir en conjunto elementos como: 1. La comisión de un ataque generalizado o 2 . Sistemático, 3. Contra una población civil y 4. Con conocimiento de dicho ataque.

La responsabilidad que surge respecto de la penalización de los crímenes de lesa humanidad, no es igual si se considera la naturaleza de cualquier otro ilícito, y por ende no puede sostenerse la extinción de la acción penal por el paso del tiempo.

En virtud de lo anterior, se erige como bien jurídicamente tutelado "la integridad física y mental del individuo, y por consiguiente no es tolerable aplicar la prescripción a una conducta como la Tortura, la cual se enmarca dentro de los delitos catalogados como de lesa humanidad.

Así las cosas, al analizarse la precita conducta bajo los presupuestos del derecho internacional se hace imprescindible la aplicación de postulados jurídicos que permitan establecer un tratamiento especial a dicho comportamiento por considerarlo violatorio de derechos fundamentales y, en específico, de garantías personalísimas, las cuales no deben ser salvaguardadas solamente por un Estado determinado, sino que han de ser amparadas y juzgadas a nivel internacional.

Finalmente, con base en ello se plantea el siguiente problema jurídico, con el cual se pretende determinar si puede haber una excepción a la regla general señalada en líneas precedentes:

¿Es pertinente darle un tratamiento al crimen de tortura bajo la calificación de lesa humanidad sin la concurrencia plena de los elementos que permiten su configuración a la luz de los instrumentos jurídicos internacionales?

\section{Tesis}

Por la naturaleza de estos crímenes, como ofensa a la dignidad inherente al ser humano, los crímenes considerados como de lesa humanidad tienen varias características específicas y entre ellas cabe resaltar que son crímenes imprescriptibles, lo que significa que el paso del tiempo no imposibilita ni la investigación o procedimiento, juzgamiento y sanción de los responsables por tribunales de justicia y por ende no es posible concebir la "ley del olvido" para crímenes que han sido cometidos contra la comunidad de las naciones y la humanidad. 
Así las cosas, a las personas responsables o sospechosas de haber cometido un crimen contra la humanidad no se le puede otorgar asilo territorial ni se les puede conceder refugio. Los responsables de crímenes de lesa humanidad no pueden invocar ninguna inmunidad o privilegio especial para sustraerse a la acción de la justicia (D’Alessio, 2008).

Por lo anterior se puede sostener que los instrumentos internacionales al elevar la tortura como delito de lesa humanidad han establecido dos aspectos de trascendental relevancia; el primero se refiere a que bajo ninguna circunstancia se debe aplicar la tortura, pues no existe ningún tipo de justificación legitima para someter a una persona a este tipo de conductas; el segundo aspecto atañe a la prescripción, es decir, que este delito de lesa humanidad con el paso del tiempo de ninguna manera puede ser olvidado, por ende, la prescripción como aspecto procesal no puede ser un impedimento para la investigación, ni el juzgamiento de este tipo de delitos bajo ningún ordenamiento estatal de derecho penal.

Se tiene entonces que la imprescriptibilidad es un aspecto material en razón al origen y el grado de afectación que ocasiona para los derechos humanos y para la comunidad de las naciones. (Donna, 2003)

Así las cosas, se sostiene que la tortura infringida a un solo individuo, puede ser considerada como delito de lesa humanidad y por tanto se encuentra sujeta a imprescriptibilidad. De manera que no debería exigirse en la totalidad de requisitos impuestos por el Estatuto de Roma para que sea considerado como de lesa humanidad y por ende imprescriptible, sino que, por el contrario, con la existencia de un solo elemento presente en la aplicación de la tortura pueda ser elevado a dicha categoría y no ser sometido a prescripción.

\section{Objetivos}

\section{A) General}

Determinar la pertinencia y tratamiento que se le puede dar a la tortura sin la concurrencia plena de los elementos establecidos en el Estatuto de Roma de la Corte Penal Internacional, para establecer la posibilidad de catalogarlo, en todo caso, como crimen de lesa humanidad.

\section{B) Específicos}

Describir el tratamiento que se da al delito de tortura a la luz de instrumentos internacionales que lo catalogan como crimen de lesa humanidad. 
- Identificar bajo qué condiciones se aplica la imprescriptibilidad en los crímenes de lesa humanidad, concretamente en el delito de tortura.

\section{Método}

Tipo de investigación: el presente estudio se enfoca desde el análisis analíticodescriptivo, documental.

Es posible sustentar el carácter analítico de la presente investigación, por cuanto no se limita al análisis de una determinada fuente, permitiendo de igual forma materializar su aspecto descriptivo; ya que en esta forma se busca recopilar la información de sectores doctrinales y jurisprudenciales que versan sobre la materia objeto de tratamiento y a su vez, mediante el método inductivo partiremos de las singularidades que versen sobre el tema para definir proporciones generales que nos permitan llegar a un conocimiento general de orden jurídico.

De igual forma es importante resaltar que la metodología trabajada en la presente investigación toma como referente los conceptos de organismos internacionales como la Corte Penal Internacional, la Corte Interamericana de Derechos Humanos y la Organización de las Naciones Unidas en conjunto con su órgano de vigilancia específica respecto de la tortura, es decir, el Comité contra la tortura de las Naciones Unidas. Es en virtud de ello que se estudian bajo la metodología propuesta instrumentos como: El Estatuto de Roma, la Convención Interamericana para Prevenir y Sancionar la Tortura, la Convención contra la Tortura y otros Tratos o Penas Crueles e Inhumanos o Degradantes, y la abundante doctrina que versa sobre el tema.

\section{Marco teórico}

\subsection{Nociones preliminares sobre la tortura}

La tortura había estado instalada en el corazón de los sistemas jurídicos bajo antiguos regímenes, así, podemos dar como ejemplo inicial los Estados occidentales antiguos y sus colonias, allí la tortura se asumía como un instrumento particular de poder de la ley, y fue necesaria la existencia de un segundo conflicto bélico mundial y el conocimiento de las monstruosidades cometidas para que se llegara a un primer reconocimiento internacional de la interdicción de la tortura.

La posguerra se caracterizó por la adopción de un gran número de resoluciones y convenciones -universales, multilaterales, regionales-e instrumentos internacionales en busca de la protección de los derechos humanos. 
En el marco de las Naciones Unidas, la Declaración Universal de los Derechos Humanos en su artículo 50, dice: "Nadie será sometido a torturas, ni a penas $o$ tratos crueles, inhumanos o degradantes".

En el mismo sentido, la antedicha declaración, de manera mucho más directa y precisa establece en su artículo $7^{\circ}$ la prohibición de "someter a una persona sin su libre consentimiento a una experiencia médica o científica”, y específicamente bajo la forma de mutilaciones, tratos crueles, torturas, suplicios, daños, ofensas a la dignidad de las personas, particularmente los tratos humillantes y degradantes.

De igual manera, a nivel regional, la Convención Americana de los Derechos Humanos, promulga la misma interdicción general en su artículo 50: "No se invocará ni admitirá como justificación del delito de tortura la existencia de circunstancias tales como estado de guerra, amenaza de guerra, estado de sitio o de emergencia, conmoción o conflicto interior, suspensión de garantías constitucionales, la inestabilidad política interna u otras emergencias o calamidades públicas; ni la peligrosidad del detenido o penado, ni la inseguridad del establecimiento carcelario o penitenciario pueden justificar la tortura"1.

Los instrumentos internacionales generales de protección de los derechos humanos no definen ni la tortura ni las penas o tratos crueles, inhumanos o degradantes. No solamente sucede ello sino que tampoco parece distinguirlos, aunque sea cierto que un mismo hecho puede ser alternativa o simultáneamente calificado de tortura o de trato inhumano o degradante.

Así, los términos "crueles" e "inhumanos" utilizados en los textos de las Naciones Unidas son sinónimos que traducen una idea de "grados" o "escalones" en la intensidad de los sufrimientos. Sin embargo conviene preguntarnos si ¿es preciso describir o dar una escala frente a las conductas que podrían ser catalogadas como tortura?

Para establecer una postura que permita dilucidar el cuestionamiento anterior, se trae a colación al Comité de Derechos Humanos, encargado de las comunicaciones individuales a los Estados por denuncias de violaciones a las disposiciones del Pacto relativo a los derechos civiles y políticos y analogía de las naciones; y en su sentir no se ha estimado adecuado fijar "distinciones muy precisas entre todas las diferentes formas de penas o de tratos prohibidos", remitiéndose así, de manera general, al artículo $1^{\circ}$ de la Convención contra la tortura y otros tratos crueles,

\footnotetext{
$\overline{1}$ Lo que se afirma hace alusión a la Resolución 39/46 de la AG. Entrada en vigor el 26 de Junio de 1987. Adoptada por Unanimidad por la Asamblea General de las Naciones Unidas el 5 de diciembre de 1984.
} 
inhumanos o degradantes que define "tortura como todo acto por el cual se inflija intencionadamente a una persona dolores o sufrimientos graves, ya sean físicos o mentales, con el fin de obtener de ella o de un tercero información o una confesión, de castigarla por un acto que haya cometido, o se sospeche que ha cometido, o de intimidar o coaccionar a esa persona o a otras, o por cualquier razón basada en cualquier tipo de discriminación, cuando dichos dolores o sufrimientos sean infligidos por un funcionario público u otra persona en el ejercicio de funciones públicas, a instigación suya, o con su consentimiento o aquiescencia”.

No se considerarán torturas los dolores o sufrimientos que sean consecuencia únicamente de sanciones legítimas, o que sean inherentes o incidentales a éstas; entendiéndose este como un único concepto; y al respecto la Corte Interamericana procede de la misma manera.

La noción jurídica del término tortura, adecuándola a nuevas técnicas de tortura "mental", particularmente de desorientación sensorial, no reduce la tortura como una típica agresión física, considerando otras dimensiones, menos perceptibles del fenómeno, pero igual de impactantes y de alta importancia; como por ejemplo: las privaciones sensoriales -aislamientos, manipulación del sueño etc.-, relacionales o afectivas -despojo de toda asistencia material y espiritual, humillación o amenazasy la incertidumbre por la suerte física -simulacro de ejecución-.

Así, como lo ha sostenido Mahiques (2003): “la aparición de las nociones ajenas de tratamientos inhumanos o degradantes se dirige a aprehender las prácticas menos espectaculares, pero no menos insidiosas de malos tratos con autonomía de la noción castrada de la tortura".

Entonces, debe decirse que los crímenes contra la humanidad surgieron hace más de medio siglo como concepto, pero solo hasta finales de la Segunda Guerra Mundial y con la existencia de la Carta del Tribunal de Nürnberg se incluyó un texto descripción que buscaba contextualizar en cierta medida los elementos que se deben comprobar estableciendo la distinción entre los crímenes de lesa humanidad y los delitos comunes. (Ambos, 2007)

Es importante recordar que no siempre ha existido un consenso respecto de la determinación y clasificación de estos delitos, y desde el Estatuto para el Tribunal Militar Internacional de Nürnberg, se les ha mencionado, pero conectados a los crímenes contra la paz o los crímenes de guerra, es decir, no podían calificarse en forma autónoma, siempre eran investigados y motivo de pronunciamiento jurisdiccional si estaban ligados a aquellos delitos.

2 En el mismo sentido se ha consagrado en la Convención contra la tortura y otros tratos crueles, inhumanos o degradantes. (1987, 26 de junio). 
Así, el artículo 6 del Estatuto consignaba: "Crímenes de lesa humanidad: El asesinato, la exterminación, la esclavitud, la deportación u otros actos inhumanos cometidos contra cualquier población civil, antes o durante la guerra, o la persecución por motivos políticos, raciales o religiosos para cometer cualquier crimen que sea de la competencia del tribunal o en relación con ese crimen, implique o el acto una violación del derecho interno del país donde se haya cometido". (Revista Internacional de la Cruz Roja [RICR], 1997, p. 696)

Sin embargo, los crímenes de lesa humanidad desde su origen, como categoría asociada con la criminalidad de guerra, han recorrido un largo camino hasta llegar a la definición incluida en el texto del Estatuto de Roma en su artículo $7^{\circ}$ bajo el cual "se entenderá por "crimen de lesa humanidad" cualquiera de los actos siguientes cuando se cometa como parte de un ataque generalizado o sistemático contra una población civil y con conocimiento de dicho ataque (...). Inciso f: Tortura”.

Se hace imprescindible entonces tener claro cuáles son los crímenes de lesa humanidad, conocer su extensión, alcance y sus repercusiones, y determinar de esta manera que dichos crímenes son juzgados por la Corte Penal Internacional, la cual se basa en el juzgamiento de personas, a efecto de, imponer una pena al responsable, contrariamente a lo que sucede en la Corte Interamericana de Derechos Humanos, donde se juzga solo a Estados, por lo cual las dos grandes esferas de protección a los derechos humanos amparadas internacionalmente son el objeto del presente estudio.

En virtud de lo anterior, también es menester hacer mención a la Convención Interamericana sobre la tortura de 1987, la cual consignó una premisa fundamental frente al tema de tortura en su Artículo $5^{\circ}$ : (...) para prevenir y sancionar la tortura, al señalar que "no se invocará ni admitirá como justificación del delito de tortura, la existencia de circunstancias tales como estado de guerra, amenaza de guerra, estado de sitio o de emergencia, conmoción o conflicto interior, suspensión de garantías constitucionales, la inestabilidad política interna u otras emergencias o calamidades públicas; la Convención extiende el concepto de tortura, no sólo a aquellos casos donde la víctima es sometida a un sufrimiento físico o mental, sino también a procedimientos que tienden a anular la personalidad de la víctima”.

La erradicación de la tortura en el mundo es uno de los grandes desafíos que asumieron las Naciones Unidas a solo unos pocos años de su fundación, para garantizar a todas las personas una protección suficiente contra la tortura y otros tratos o penas crueles, inhumanos o degradantes.

La Organización fue adoptando paulatinamente normas de aplicación universal que finalmente fueron consagradas en declaraciones y convenios internacionales; y la 
culminación de este proceso normativo en el ámbito de la lucha frente a la tortura, se consolido en la Convención contra la Tortura y Otros Tratos o Penas Crueles o Inhumanos o Degradantes, del cual, su texto especifica que los Estados signatarios prohibirán la tortura en sus legislaciones nacionales, pero también denota explícitamente que no existe un orden superior o circunstancia excepcional para invocar la justificación de los actos de tortura.

Este texto no se limitó al escrito de una serie de artículos sino que también instituyo un órgano de vigilancia que garantizaría la observancia y la aplicación de la convención el cual se denominó como el Comité contra la Tortura órgano de las naciones Unidas encargado de la vigilancia y salvaguarda de los derechos humanos.

De lo expuesto puede colegirse la preocupación de la comunidad internacional, siendo una reacción en medio de la conmoción por los grandes crímenes masivos del siglo XX.

La comisión de los delitos internacionales cometidos fuera del marco de un conflicto armado internacional ha sido un paso extraordinario en el proceso de tipificar conductas intolerables para cualquiera de los habitantes de la comunidad de las naciones, disminuyendo gradualmente la posibilidad de que ellos queden impunes y así, en la medida de lo posible, prevenir su comisión.

\subsection{Los crímenes de lesa humanidad a la luz del derecho penal internacional}

Bajo la óptica de los instrumentos internacionales es posible interpretar que el derecho internacional genera tutela del precioso bien que es la vida y la integridad de las personas, también tipificando ciertos hechos como crímenes internacionales; independientemente que tales hechos constituyan delito en el derecho interno.

Estos crímenes, genéricamente denominados crímenes contra la humanidad o lesa humanidad, no necesariamente han de quedar configurados porque los hechos imputables se den en una situación de conflicto armado internacional o no internacional, sino que los crímenes de lesa humanidad en razón a su naturaleza y escala no exigen para su tipificación una situación de guerra, y lamentablemente, también pueden producirse tales actos aun en tiempo de paz.

Así las cosas, haciendo mención a la importancia conceptual que implica el Estatuto de Roma de la Corte Penal Internacional, conviene resaltar la presencia de los elementos que, por regla general, configuran la tortura como crimen de lesa humanidad, y así las cosas se tiene en razón de su artículo $7^{\circ}: 1$. Se cometa como parte de un ataque generalizado o 2. Sistemático 3. Contra la población civil y 4. Con conocimiento de dicho ataque. 
De acuerdo a los precitos requisitos, se describe la situación o contexto en el que debe cometerse la conducta para constituir un crimen contra la humanidad; el acto concreto subsumible se constituye en una participación en un ataque generalizado o sistemático contra una población civil y con conocimiento de dicho ataque.

El carácter doloso de los crímenes de competencia de la Corte Penal Internacional y la inclusión de este elemento en el tipo de los crímenes contra la humanidad tiene como resultado la concepción de cada acto en concreto como una aportación al ataque a gran escala que constituye un solo hecho de alto impacto que afecta a un grupo de personas o hechos pequeños pero repetitivos en distintas victimas.

A la vez, el carácter sistemático, vale decir, planeado con minucia y repetitivo en un tiempo continuo o discontinuo, exige que el dolo del autor también se extienda también al contexto, aunque no tuviera conocimiento de todas las características del ataque ni de los detalles precisos del plan o la política del Estado u organización; basta con que conozca que su concreta conducta dolosa se enmarca dentro de una acción conjunta más amplia, bajo un tipo subjetivo, teniendo en cuenta que con cualquier tipo de dolo, tanto respecto de la conducta concreta realizada como respecto del conocimiento del ataque.

Estos elementos mencionados en líneas anteriores fue introducido con el argumento de que el Derecho Internacional consuetudinario no había reconocido nunca como crimen contra la humanidad cualquier comisión de un acto inhumano aislado, y que por el contrario, garantizar su pertenencia al ámbito había de exigir que el acto fuera parte de una "campaña mayor" de atrocidades contra civiles.

De esta manera, los adjetivos "generalizado" y "sistemático" que califican el ataque deben exigirse conjunta o disyuntivamente -bajo la regla general-, y por ende la exigencia de que los actos formaran parte de un ataque excluía el peligro que bajo el adjetivo "generalizado" se pretendiera la inclusión de olas de crímenes comunes que no debían pertenecer a la jurisdicción del tribunal.

A su vez, el "ataque sistematizado contra una población civil" debe entenderse como una línea de conducta que implique la comisión múltiple de los actos en cuestión contra una población civil en cumplimiento de una política de un Estado o de una organización de cometer esos actos o promover esa política estimulando activamente el ataque contra una población. (Instituto de Promoción de Derechos Humanos [IPDH], 1997).

La inclusión del delito de tortura como de lesa humanidad en la Convención contra la Tortura de 1984, no exige que el sujeto activo sea un funcionario público u otra persona en el ejercicio de sus funciones públicas o con su consentimiento o 
aquiescencia, lo que explica que en el estatuto pueden ser también miembros de organizaciones no estatales.

Tampoco se exige, a diferencia de la definición de la tortura en la Convención, que la conducta se realice con un intención determinada, como por ejemplo la de obtener información o confesión, lo que desvirtúa el concepto tradicional de tortura, para convertirlo simplemente en la causación dolosa de dolores o sufrimientos físicos o mentales graves a la personas sometidas a la custodia o control del sujeto activo, que no sean inherentes o incidentales a la imposición de sanciones legítimas, y que sean cometidos en el marco generalizado y sistemático. (Zaffaroni, 2000)

\subsection{El delito de tortura y su tratamiento como crimen de lesa humanidad}

Desde la Declaración Universal de Derechos Humanos de 1948, existe conciencia acerca de no tolerar ciertas conductas, pues la comunidad internacional es agraviada o afectada cuando se producen estos delitos.

La tortura es entonces uno de aquellos delitos que destruyen lo más preciado de la persona humana, es así, que el Pacto Internacional de Derechos Civiles y Políticos regula su prohibición absoluta en el artículo 7, como ya se dijo.

A su vez, en el sistema interamericano de protección, la Convención Americana sobre Derechos Humanos prohíbe la tortura en el artículo 5: "Derecho a la integridad personal:

1. Toda persona tiene derecho a que se respete su integridad física, psíquica y moral.

2. Nadie debe ser sometido a torturas ni a penas o tratos crueles, inhumanos o degradantes. Toda persona privada de libertad será tratada con el respeto debido a la dignidad inherente al ser humano".

En forma análoga a la ampliación de protección del Pacto Internacional de Derechos Civiles y Políticos en situaciones de excepción, el artículo 27 numeral 2 regula que: "La disposición precedente no autoriza la suspensión de los derechos determinados en los siguientes Artículos: (...) $5^{\circ}$ (Derecho a la Integridad Personal) (...), ni de las garantías judiciales indispensables para la protección de tales derechos".

Es decir, la protección de la integridad personal pertenece al núcleo inderogable que no puede ser suspendido ni suprimido jamás, cualquiera sea la circunstancia en que se encuentre un Estado. 
En 1975, la Organización de Naciones Unidas aprobó una Declaración sobre la Protección de todas las Personas contra la Tortura y otros Tratos o Penas Crueles, Inhumanos o Degradantes (Resolución 3452 de la $\mathrm{ONU}$ ), que fue la base para que luego se aprobara la Convención contra la Tortura, el 10 de diciembre de 1984.

Así las cosas, se observa en la Declaración que la tortura es considerada como "ofensa a la dignidad humana" y la definición permite establecer esta clase de delito como crimen de lesa humanidad.

\subsection{La imprescriptibilidad de la tortura considerada como crimen de lesa humanidad}

Al respecto, Beccaria (1990) afirma: “...los delitos atroces que dejan en los hombres una larga memoria, sí están probados no merecen prescripción a favor del reo. Los delitos leves, en cambio deben prescribir para librar así la incertidumbre de la vida de las personas. Fundamenta su criterio en la consideración objetiva del mal producido".

Lo anterior se erige como el fundamento de la imprescriptibilidad de los delitos de lesa humanidad. (Pastor, 1993, p.24-26)

Puede notarse una diferencia entre aquellos delitos considerados graves y donde se aplica una prescripción más larga e incluso la imprescriptibilidad como mecanismo de protección del estado.

Por otra vertiente van los delitos menos graves donde no existe limitación para la aplicación de la prescripción y donde no opera la imprescriptibilidad.

Para algunos autores la prescripción no es sino un impedimento u obstáculo puesto para la iniciación o prosecución de un procedimiento penal, sin anular o reprimir el derecho a castigar, que permanece intocado como facultad propia del Estado, pero sin la posibilidad de actualizarse en función del tiempo transcurrido. (Vela, 1995)

Welzel (1956) sostiene que "la prescripción de la acción tiene un carácter meramente procesal, vale decir es mero obstáculo para el proceso” (p.257).

Por su parte, Maurach (1962) señala que "la prescripción penal impide la propia incoación del proceso penal" (p. 624).

Lo que se pierde por parte del Estado en estos casos, por razón del simple transcurso del tiempo, es el derecho mismo de perseguir y en su caso ejecutar la sanción, es 
decir, que hay una afectación al ius puniendi que impide al derecho penal alcanzar sus fines, sean estos represivos, reeducativos o tendiente a la readaptación social o resocialización del delincuente.

Para Vera Barros (1960); "la prescripción es un instituto de derecho material, porque lo que caduca con el transcurso del tiempo es la pretensión punitiva del estado: su derecho a castigar en el caso concreto" (p.118).

Así las cosas, se señala que si la prescripción se basa en la enmienda "natural" del autor de un hecho punible, en la innecesaria o contraproducente aplicación de una pena tardía o en cualquier otra explicación que se vincule a la teoría de la pena, entonces su naturaleza jurídica será evidentemente, de derecho material, dado que la prescripción, así extingue la potestad represiva del estado.

Sin embargo, no se puede negar que el criminal contra la humanidad excede con mucho en su conducta el contenido ilícito de cualquier otro delito; no puede ni siquiera pensarse en una retribución, porque no hay forma humana de retribuir el dolor provocado por un crimen de esta naturaleza, o sea que las propias teorías sobre una idea retributiva deben reconocer su fracaso ante estos hechos.

No puede sostenerse razonablemente que sea menester garantizar la extinción de la acción penal por el paso del tiempo en crímenes de esta naturaleza, en razón de una intolerable irracionalidad; en el ejercicio de una acción penal contra un criminal de lesa humanidad por mucho que hayan pasado los años no está legitimado para exigir la prescripción de las acciones emergentes de estos delitos; por el contrario, si lo hiciese sufriría un grave desmedro ético.

La imprescriptibilidad que hoy consagran las leyes internacionales, es fruto de la carencia de legitimidad del derecho penal para contener el poder punitivo en estos casos. No hay argumento jurídico ni ético que le permita invocar la prescripción en los crímenes de lesa humanidad; el derecho penal no puede invocar la prescripción, porque está consagrando una norma como fuente de impunidad que legitimarían las consecuencias de los horrores que ha vivido el mundo durante el siglo XX.

La Convención sobre Imprescriptibilidad de los Crímenes de guerra y de los Crímenes de Lesa Humanidad, fue aprobada por resolución 2391 de la Asamblea General, y entró en vigor el 11 de noviembre de 1970, como culminación de un largo proceso que comenzó en los primeros años de la década del sesenta, cuando la prescripción amenazaba con convertirse en fuente de impunidad de los crímenes de guerra practicados durante la segunda guerra mundial por los vencidos. (Albanesse, 2004) 
De cualquier manera, es necesario recordar que el derecho internacional consuetudinario establece que cierto tipo de crímenes internacionales son imprescriptibles.

Así por ejemplo, son imprescriptibles los crímenes de lesa humanidad. No obstante, hay que tener en cuenta que la imprescriptibilidad no se predica de todos los crímenes internacionales, pues no es un elemento inherente a toda infracción penal internacional y sólo se predica respecto de ciertos crímenes internacionales, los crímenes de lesa humanidad, el genocidio y el apartheid (estos dos últimos son una modalidad específica de crimen de lesa humanidad).

Así, la tortura aun cuando es crimen internacional no es imprescriptible per se, salvo cuando estos actos son cometidos dentro de una práctica a gran escala o sistemática teniendo en cuenta el elemento volitivo del sujeto activo que realiza este delito, es decir, si la intención en el plan de aplicación de la tortura a una o a varias personas en efecto se dirige a la destrucción o el ataque contra una población civil, pues en ese evento, se convierten jurídicamente en otra entidad, a saber un crimen de lesa humanidad.

El sacrificio de este principio como lo es la prescripción sólo puede entrar en consideración en situaciones excepcionales, y frente a las cuales la imprescriptibilidad aparece como el único recurso para la persecución de delitos de gravedad extrema cometidos por regímenes en forma generalizada y sistemática donde exista una voluntad criminal dirigida en contra de una población civil. (Ziffer, 2005)

Sin embargo, es posible determinar que por la naturaleza jurídica de los delitos de lesa humanidad en especifico la tortura a un individuo que haya sido realizada con un acto bestial y un salvajismo irracional absoluto, no es un hecho generalizado por que lo padece una sola persona, o un grupo reducido de personas pero si se puede considerarse como sistemático debido a la gravedad de la violación contra la misma víctima, es decir fue sistemático en contra de la misma victima ya que fue ella la que padece repetidamente los actos criminales dentro de un determinado periodo de tiempo y cuyo objetivo es destruirla o devastarla.

No es posible distinguir entre tipos de tortura o tomar un delito común como el de lesiones a una tortura impuesta a un individuo o a varios, a causa de los niveles de crueldad que implican la aplicación de una tortura y este así mismo esta conducta es elevada a la categoría de crimen de lesa humanidad, que si bien es cierto no es un ataque generalizado y el fin seguramente no será el de destruir a un grupo determinado de personas, si es una acción en contra de la población civil un individuo o grupo reducido de personas la cual es parte de una población civil, es por ello que no se deben tomar para este delito en concreto, las palabras "generalizado" y 
"sistematizado" conjuntamente, es preciso en algunos casos tener en cuenta el hecho que solamente se presente un elemento dentro de la acción de la tortura, se debe estudiar el caso en concreto, es irracional pensar que una persona sea sometida a una tortura por cualquier circunstancia sea indeterminada la voluntad del actor y se considere como un delito común cuando la gravedad de la conducta es catalogada como de lesa humanidad, y por tanto sujeta de imprescriptibilidad.

\section{Conclusiones}

1. Nadie podrá ser torturado bajo ninguna circunstancia, es decir, no existe ningún tipo de justificación, estado de excepción o causa que permita legitimar la aplicación de tortura a un individuo. Esta última cuestión ha sido un esfuerzo de los distintos elementos internacionales por erradicar la práctica de tortura.

2. Para el delito de tortura, el cual es catalogado como crimen de lesa humanidad, es inoperante exigir en conjunto las cuatro características que designa el Estatuto de Roma para que un delito pueda recibir el tratamiento de lesa humanidad: "como parte de un ataque generalizado, sistemático, contra una población civil y con conocimiento de dicho ataque". Concluimos entonces que con la presencia de un solo elemento al momento de someter a un individuo a una tortura no se puede concebir como un hecho aislado, por el contrario, por la gravedad y la crueldad perpetrada al individuo en una tortura en contra de las reglas internacionales, hay que considerarlo como crimen de lesa humanidad porque trasgrede la dignidad de la persona y los derechos humanos de la misma.

3. No es posible tratar a un individuo que ha padecido la crueldad de la tortura como una minoría despojándola de su derecho de denunciar este crimen en cualquier tiempo, por hecho de que los cuatro elementos anteriormente mencionados no se presenten de manera contigua en el momento de la consecución del crimen. Hay que resaltar que un individuo soporta de manera sistematizada, planeada minuciosamente, al someterse a cualquier tipo de vejámenes con el fin de causar detrimentos graves tanto físicos como mentales con un fin indeterminado del victimario, de una magnitud tal que deja secuelas de por vida en una víctima, por tanto debe considerarse este hecho como crimen contra la humanidad que debe estar sujeto a la imprescriptibilidad. No se trata de considerar cualquier tipo o lesión como de lesa humanidad, sino por el contrario, de tener claro los niveles de daño que implican infringir a una persona una tortura y con base en ese hecho tan irracionalmente despiadado se le dé un tratamiento como crimen de lesa humanidad.

4. La base de la imprescriptibilidad se encuentra en una política criminal que tiene por objeto el reconocimiento del derecho a la verdad de lo sucedido, la no repetición de estos actos, los mandatos de la comunidad internacional y la reparación social, 
a su vez, tiene un efecto preventivo ya que un hecho impune puede generar mayores daños en la sociedad democrática, que aplicar la justicia punitiva. La prescripción como figura del derecho procesal penal tiene mayor peso jurídico cuando se evalúan los delitos de lesa humanidad, ya que con esta concepción no se extingue, ni se renuncia a la función punitiva del Estado; en ese sentido, por política criminal la prescripción solo opera en delitos menos graves.

\section{Referencias}

Albanese, S. (2004, junio). Curso de Especialización en Derecho Penal y Procesal Penal. Facultad de Derecho. Universidad Nacional de Mar del Plata. Seminario de Derechos Humanos.

Ambos, K. (2007). Crímenes de Lesa Humanidad. Un dictamen para el Fiscal del Tribunal Internacional de Mixto de la ONU para Timor Oriental. Argentina: Colección de autores de derecho penal.

Beccaria, C. (1990). De los delitos y de las penas. Bogotá: Temis.

Convención Interamericana sobre la Tortura. (s.f.). Recuperado de http:// www.un.org/es

Corte Interamericana de Derechos Humanos. (s.f.). Recuperado de http:// www.corteidh.or.cr/

Corte Penal Internacional. (s.f.). Recuperado de http://www.un.org/spanish/news/ facts/iccfact.htm

Cruz Roja Internacional. (1997, 1 de nov.). Revista Internacional de la Cruz Roja, (144), 696.

D’Alessio, A.J. (2008). Los delitos de lesa humanidad. Buenos Aires: AbeledoPerrot.

Donna, E.A. (2003). Delitos contra las personas. Buenos Aires: Rubinzal Culzoni. Revista de Derecho penal.

Estatuto de Roma. (1998, 17 de jul.). Doc.A/CONF.183/9. Recuperado de http:// www.un.org/spanish/news/facts/iccfact.htm

Foucault, M. (1995). Vigilar y castigar. México: Cal y Arena.

Instituto de Promoción de Derechos Humanos. (1997). Hechos y Derechos. Buenos Aires. Revista de Derecho Penal. 
Mahiques, C.A. (2003). la noción jurídica de tortura y de penas y tratamientos crueles, inhumanos o degradantes en el derecho penal internacional. Argentina: Universitas, Universidad Católica de Argentina.

Organización de las Naciones Unidas [ONU]. (s.f.). Recuperado de http:// www.un.org/es

Organización de las Naciones Unidas [ONU]. (1992). Derechos humanos. Comité contra la Tortura. Folleto Informativo (17).

Pastor, D.R. (1993). Prescripción de la persecución y Código Procesal Penal. Argentina: Del Puerto.

Parenti, P. F. (2007). Crímenes contra la humanidad. Origen y evolución de la figura, y un análisis de sus elementos centrales en el Estatuto de Roma. Argentina: Ad-Hoc.

Maurach, R. (1962). Tratado de derecho penal, T. II. S.1.: Ariel.

UNAM. (2004, enero-junio). Instituto de Investigaciones Jurídicas. Revista Mexicana de Justicia, (1), 27.

Vela, S. (1995, Marzo). La prescripción en materia penal. México: Trillas.

Vera, O. (1960). La prescripción penal en el Código Penal. Argentina: Facultad de Derecho de Córdoba.

Welzel, H. (1956). Derecho penal parte general. Buenos Aires: Roque Desalma.

Zaffaroni, R. E. (2000). Notas sobre el fundamento de la imprescriptibilidad de los crímenes de lesa humanidad. Argentina: Del Puerto. Revista Nueva Doctrina Penal.

Ziffer, P. (2005). El principio de legalidad y la imprescriptibilidad de los delitos de lesa humanidad. En J. Maier (homenaje al profesor). Estudios sobre justicia penal. Buenos Aires: Del Puerto. 